\title{
Épocas de semeadura do trigo para a região Centro-Sul Mato- Grossense
}

\author{
Elijanara Raissa Silva1, Juliana Nunes de Oliveira $^{2}$, Crislane Pereira Rubio ${ }^{2}$, Gabriel \\ Albuquerque de Lyra², Fábio Steiner ${ }^{1}$
}

\author{
${ }^{1}$ Universidade Estadual de Mato Grosso do Sul, Unidade Universitária de Cassilândia, Cassilândia, Mato Grosso do Sul, Brasil. E- \\ mail: raissa@agronoma.eng.br \\ ${ }^{2}$ Instituto Federal de Educação, Ciência e Tecnologia de Mato Grosso, Campus São Vicente, Santo Antônio do Leverger, Mato \\ Grosso, Brasil. E-mail: juliana.agronomia@hotmail.com, crislaine_rubio@hotmail.com, gabriel.lyra@svc.ifmt.edu.br
}

Recebido: 13/06/2017; Aceito: 29/11/2017.

\section{RESUMO}

A época de semeadura é um dos principais fatores que afeta o rendimento da cultura do trigo na região do CentroOeste, devido aos riscos de ocorrência de deficiência hídrica no período de outono-inverno. O objetivo deste trabalho foi identificar a melhor época de semeadura e avaliar o potencial de rendimento da cultura de trigo (Triticum aestivum L., cv. Valente) para a região Centro-Sul Mato-Grossense. O experimento foi realizado no município de Santo Antônio do Leverger (MT), na safra 2013. O delineamento experimental foi em blocos ao acaso com quatro repetições e cinco tratamentos, sendo eles compostos por cincos épocas de semeadura: 24 de fevereiro, 03, 10, 17 e 24 de março de 2013. Os resultados reportaram que as épocas de semeadura testadas não afetaram significativamente $(p>0,05)$ a altura das plantas e o peso do hectolitro. A população final de plantas, a massa de 1000 grãos e a produtividade de grãos foram afetadas significativamente $(\mathrm{p}<0,05)$ pelas diferentes épocas de semeadura. Com base nos resultados conclui-se que as semeaduras realizadas nos dias 03 e 24 de março em Santo Antônio do Leverger- MT são as mais adequadas para o cultivar de trigo Valente por proporcionarem as maiores produtividades.

Palavras-chave: Triticum aestivum L., Cerrado, adaptabilidade

\section{Wheat sowing times for the south-central region of Mato Grosso, Brazil}

\begin{abstract}
The sowing season is one of the main factors affecting wheat yield in the Central Brazil region, due to the risk of occurrence of water deficiency in the autumn-winter period. The objective of this work was to identify the best sowing season and to evaluate the yield potential of the wheat crop (Triticum aestivum L., cv. Valente) For the Center-South Mato Grosso region. The experiment was carried out in the municipality of Santo Antônio do Leverger (MT), in the crop year 2013. The experimental design was a randomized block design with four replicates and five treatments, consisting of five sowing times: February 24, March 3, 10, 17 and 24, 2013. The results reported that the sowing times tested did not $(\mathrm{p}>0.05)$ significantly affected plant height and hectoliter weight. The final population of plants, the mass of 1000 grains and the grain yield were significantly affected $(\mathrm{p}<0.05)$ by the different sowing times. On the basis of the results, it was concluded that the sowing performed on March 03 and 24 in Santo Antônio do Leverger-MT, are the most suitable for the cultivar Valente of wheat, because they provide the highest grain yields in dry wheat.
\end{abstract}

Key words: Triticum aestivum L., Cerrado, adaptability. 


\section{Introdução}

O trigo (Triticum aestivum L.) é uma das culturas de maior importância econômica para o Brasil e o mundo. Anualmente, são produzidas mais de 750 milhões de toneladas no mundo; o Brasil contribuiu com cerca de 6,5 milhões de toneladas, na safra 2016/2017 (USDA, 2017). No entanto, a produção nacional do trigo está concentrada na região Sul, responsável por mais de $94 \%$ da produção do país na safra 2016/2017, ao passo que a produção de trigo da região Centro-Oeste representou apenas 1,6\% da produção nacional (CONAB, 2017).

$\mathrm{O}$ principal desafio para o cultivo de trigo na região Centro-Oeste do Brasil se deve, principalmente, pelo inverno seco, o que praticamente impossibilita o seu cultivo em áreas sem irrigação. Portanto, a época de semeadura é considerada um dos principais fatores que afetam o rendimento da cultura do trigo, principalmente, devido aos riscos de restrição hídrica ao longo do ciclo da cultura na região Centro-Sul. De acordo com Silva et al. (2011), o potencial de rendimento de grãos pode ser maximizado pela escolha adequada da época de semeadura, sem que se onere o custo de produção.

A escolha adequada da época de semeadura permite que os diferentes estádios de crescimento e desenvolvimento do trigo ocorram em condições climáticas favoráveis, possibilitando a obtenção de altos níveis de produtividade de grãos (ROOZEBOOM et al., 2008; BORÉM; SCHEEREN, 2015). De acordo com Ribeiro et al. (2009), as condições de temperatura e o fotoperíodo são fatores que interferem na duração dos estádios de desenvolvimento da cultura do trigo e, consequentemente, nos componentes de produção e no rendimento de grãos. No entanto, a resposta a estes fatores do ambiente é dependente da época de semeadura e do genótipo utilizado.

Estudos para a região Sul do Brasil reportaram que o manejo da época de semeadura na cultura do trigo tem possibilitado o incremento na produtividade de grãos de até $80 \%$ (BASSOI et al., 2005; SILVA et al., 2011). No entanto, estudos que visam avaliar a melhor época de semeadura do trigo para o cultivo de sequeiro na região Centro-Oeste do Brasil ainda são incipientes e inconclusivos. Estes estudos são necessários a fim de minimizar os riscos ambientais e maximizar o potencial de rendimento de grãos (CUNHA et al., 2011).
O presente estudo teve como objetivo identificar a melhor época de semeadura e avaliar o potencial de rendimento da cultura do trigo em condições de sequeiro para a região Centro-Sul Mato-Grossense.

\section{Material e Métodos}

$\mathrm{O}$ experimento foi realizado na área experimental do Instituto Federal de Educação, Ciência e Tecnologia de Mato Grosso - IFMT, Campus São Vicente, localizado no município de Santo Antônio do Leverger (1549'12" de latitude Sul; 55²5'4" de longitude Oeste e altitude média de $770 \mathrm{~m}$ ), região Centro-Sul do Estado de Mato Grosso, no período de fevereiro a junho de 2013.

O clima da região, segundo classificação de Köppen, é do tipo Aw, caracterizado como clima tropical úmido, com verão chuvoso e inverno seco, com precipitação média anual de $2.000 \mathrm{~mm}$ e temperatura média anual de $23,3{ }^{\circ} \mathrm{C}$. Os dados de precipitação pluvial e temperatura média diária durante a realização do experimento são mostrados na Figura 1.

$\mathrm{O}$ solo da área experimental foi classificado como Latossolo Vermelho distrófico, de textura argilosa (SANTOS et al., 2013). As propriedades químicas do solo na camada de $0-0,20 \mathrm{~m}$ são mostradas na Tabela 1 .

O delineamento experimental adotado foi em blocos casualizados (DBC), com cinco tratamentos e quatro repetições. Os tratamentos foram constituídos de cinco épocas de semeadura: 24 de fevereiro de 2013; 03 de março de 2013; 10 de março de 2013; 17 de março de 2013; 24 de março de 2013. Cada unidade experimental foi constituída de $2,0 \mathrm{~m}$ de largura por $4,0 \mathrm{~m}$ de comprimento, totalizando uma área de $8,0 \mathrm{~m}^{2}$. A área útil das parcelas foi de $3,6 \mathrm{~m}^{2}$ considerando-se as seis linhas centrais, e descartando $0,5 \mathrm{~m}$ nas extremidades.

A semeadura foi realizada manualmente utilizando o cultivar Valente. As sementes foram semeadas à $2-3 \mathrm{~cm}$ de profundidade, em linhas espaçadas de $0,20 \mathrm{~m}$ utilizando-se 450 sementes por $\mathrm{m}^{2}$. A adubação de base constou da aplicação de $200 \mathrm{~kg} \mathrm{ha}^{-1}$ da formulação 0430-16 no sulco de semeadura. As sementes foram tratadas com CropStar ${ }^{\circledR}$ na dose de $3 \mathrm{~mL}$ para $1 \mathrm{~kg}$ de semente. $\mathrm{O}$ controle de plantas daninhas foi realizado com capinas manuais e com aplicação de $15 \mathrm{~mL}$ do herbicida Lorsban ${ }^{\circledR} 480 \mathrm{BR}$ para $10 \mathrm{~L}$ de água.

Tabela 1. Análise química do solo da área experimental do IFMT- Campus São Vicente. Santo Antônio do Leverger-MT, 2013

\begin{tabular}{|c|c|c|c|c|c|c|c|c|c|c|}
\hline Amostra & $\begin{array}{c}\mathrm{pH} \\
\left(\mathrm{CaCl}_{2}\right)\end{array}$ & $\begin{array}{c}\mathrm{P} \\
\text { Mehlich-1 } \\
\end{array}$ & K & $\mathrm{Ca}$ & $\mathrm{Mg}$ & $\mathrm{H}^{+}+\mathrm{Al}^{+3}$ & CTC & V & M. O. & $\begin{array}{c}\mathrm{Zn}- \\
\text { DTPA }\end{array}$ \\
\hline & & $\mathrm{mg} \mathrm{dm} \mathrm{d}^{-3}$ & & --------- & $-\mathrm{cmol}_{\mathrm{c}}$ & ------- & & $\%$ & $\mathrm{~g} \mathrm{dm}^{-3}$ & $\mathrm{mg} \mathrm{kg}^{-1}$ \\
\hline $0-20 \mathrm{~m}$ & 5,0 & 1,1 & 0,11 & 0,38 & 0,33 & 7,34 & 8,16 & 10,0 & 29,2 & 2,4 \\
\hline
\end{tabular}




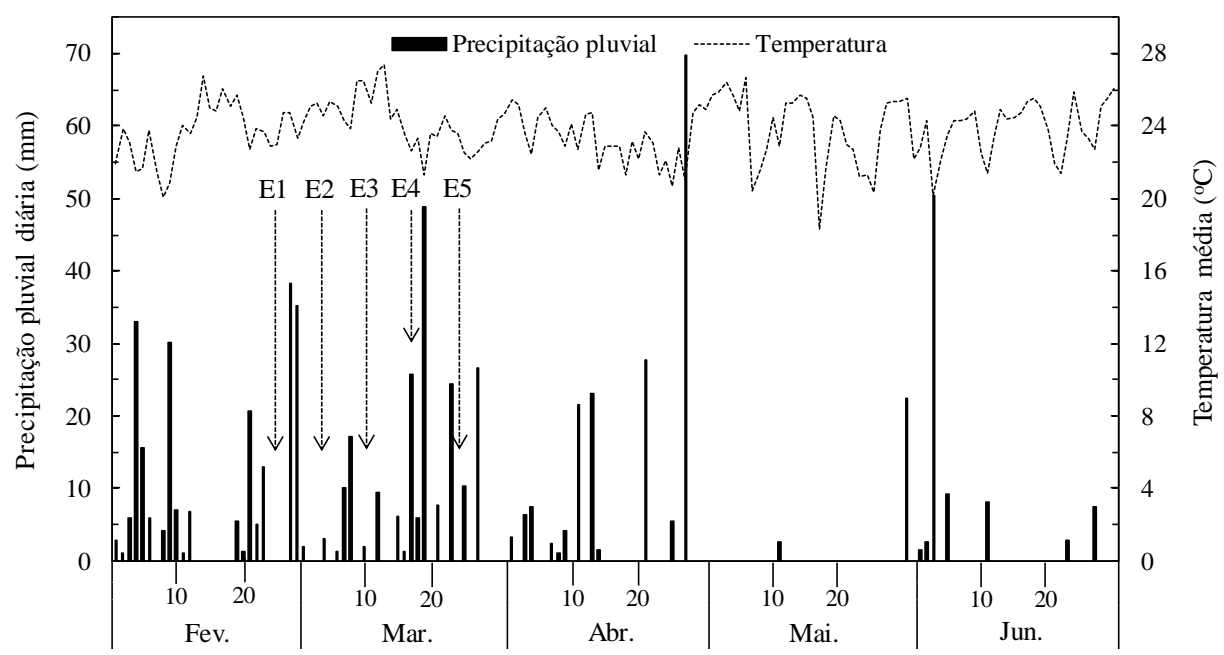

Figura 1. Precipitação pluvial $(\mathrm{mm})$ e temperatura média diária $\left({ }^{\circ} \mathrm{C}\right)$ durante a realização dos experimentos com diferentes épocas de semeadura da cultura de trigo no munícipio de Santo Antônio do Leverger-MT. $E_{1}, E_{2}, E_{3}, E_{4}$ e $E_{5}$ correspondem as cinco diferentes épocas de semeadura do trigo.

Na maturação da cultura, realizou-se a colheita manual do trigo, coletando-se todas as espigas contidas na área útil e em seguida avaliando-se o desempenho produtivo da cultura. O desempenho produtivo da cultura foi avaliado perante os seguintes caracteres: população final de plantas (contagem das plantas da area útil); altura de planta (distância mensurada do nível do solo até a extremidade da espiga); massa de 1000 grãos (pesagem de oito subamostras de 100 grãos por tratamento, com a massa corrigida para $130 \mathrm{~g} \mathrm{~kg}^{-1} \mathrm{de}$ teor de água - base úmida - "b.u."); peso do hectolitro (mensurado através da massa de grãos contido em um volume de $100 \mathrm{~mL}$ ); produtividade de grãos, obtida através da pesagem dos grãos oriundos das áreas úteis das parcelas experimentais ( $\mathrm{g}$ parcela ${ }^{-1}$ ), a qual foi convertida para $\mathrm{kg} \mathrm{ha}^{-1}$ e padronizada para $130 \mathrm{~g} \mathrm{~kg}^{-1}$ (b.u.).

Os dados foram previamente submetidos ao teste de Kolmogorov-Smirnov $(p<0,05)$ e homogeneidade de variância com o teste de Levene $(p<0,05)$, e então submetidos à análise de variância aplicando-se o teste $\mathrm{F}$ a 5\% de significância por meio do programa estatístico ASSISTAT. Os efeitos das épocas de semeadura foram comparados pelo teste de Tukey a $5 \%$ de probabilidade.

\section{Resultados e Discussão}

As diferentes épocas de semeadura do trigo não afetaram significativamente $(\mathrm{p}>0,05)$ a altura das plantas e o peso hectolítrico (Tabela 2). Estes resultados indicam que a distribuição de chuvas e a temperatura no período de crescimento e desenvolvimento das plantas de trigo foram adequadas para a cultura (Figura 1), resultando em plantas com o mesmo porte de altura em todas as épocas de semeadura testadas.
Quando a cultura do trigo de sequeiro é cultivada em condições de precipitação pluvial e temperaturas adequadas para o seu crescimento e desenvolvimento, a altura de planta tende a se manter constante. Durante a condução do experimento, os índices de precipitação pluvial variaram de 350 a $460 \mathrm{~mm}$ e a temperatura média variou de 18 a $27{ }^{\circ} \mathrm{C}$ (Figura 1). A temperatura ideal para o adequado crescimento e desenvolvimento do trigo é em torno de $20 \mathrm{oC}$; para o afilhamento de 15 a $20{ }^{\circ} \mathrm{C}$ e para o desenvolvimento de folhas entre $20 \mathrm{e}$ $25{ }^{\circ} \mathrm{C}$. A necessidade de água durante o ciclo da cultura nas condições de sequeiro do Cerrado brasileiro está em torno de 430 mm (BORÉM; SCHEEREN, 2015).

O menor índice de chuva ocorrido após o espigamento do trigo, especialmente no mês de maio, também favoreceu a produção de grãos de alta qualidade, como pode ser verificado pelos valores do peso hectolítrico superiores a 78 (Tabela 2). Quando o peso hectolítrico tem valor igual ou superior a 78, o grão de trigo é classificado como do Tipo 1 (BORÉM; SCHEEREN, 2015), portanto, verifica-se em todas as épocas de semeadura testadas a qualidade dos grãos de trigo produzido foi alta.

O peso hectolítrico é uma variável que está estreitamente associada à densidade e à qualidade do grão, as quais são diretamente influenciadas pela interação genética com as condições ambientais, especialmente com a ocorrência de chuvas na época de colheita que compromete a qualidade dos grãos de trigo produzido (BORÉM; SCHEEREN, 2015).

A população final de plantas, a massa de 1000 grãos e a produtividade do trigo foi afetada significativamente $(\mathrm{p}<0,05)$ pelas diferentes épocas de semeadura da cultura do trigo na região Centro-Sul Mato-Grossense (Tabela 2). 
Tabela 2. População final de plantas, altura de planta, massa de 1000 grãos, peso do hectolitro e produtividade de grãos da cultura do trigo (Triticum aestivum L., cv. Valente) semeada em cinco diferentes épocas no munícipio de Santo Antônio do Leverger-MT, região Centro-Sul Mato-Grossense

\begin{tabular}{cccccc}
\hline Época de semeadura & $\begin{array}{c}\text { População final de } \\
\text { plantas }\left(\mathrm{m}^{2}\right)\end{array}$ & $\begin{array}{c}\text { Altura de planta } \\
(\mathrm{m})\end{array}$ & $\begin{array}{c}\text { Peso hectolítrico } \\
(\mathrm{g})\end{array}$ & $\begin{array}{c}\text { Massa de } 1000 \text { grãos } \\
(\mathrm{g})\end{array}$ & $\begin{array}{c}\text { Produtividade de } \\
\text { grãos } \\
\left(\mathrm{kg} \mathrm{ha}^{-1}\right)\end{array}$ \\
\hline $\mathrm{E}_{1}(24 / 02 / 2013)$ & $271 \mathrm{~b}$ & $0,79 \mathrm{a}$ & $78,6 \mathrm{a}$ & $37,42 \mathrm{ab}$ & $1.981 \mathrm{~b}$ \\
$\mathrm{E}_{2}(03 / 03 / 2013)$ & $310 \mathrm{ab}$ & $0,74 \mathrm{a}$ & $78,1 \mathrm{a}$ & $39,57 \mathrm{a}$ & $2.425 \mathrm{a}$ \\
$\mathrm{E}_{3}(10 / 03 / 2013)$ & $367 \mathrm{a}$ & $0,78 \mathrm{a}$ & $79,3 \mathrm{a}$ & $38,70 \mathrm{a}$ & $1.842 \mathrm{bc}$ \\
$\mathrm{E}_{4}(17 / 03 / 2013)$ & $365 \mathrm{a}$ & $0,77 \mathrm{a}$ & $79,3 \mathrm{a}$ & $36,15 \mathrm{~b}$ & $1.512 \mathrm{c}$ \\
$\mathrm{E}_{5}(24 / 03 / 2013)$ & $338 \mathrm{a}$ & $0,76 \mathrm{a}$ & $80,5 \mathrm{a}$ & $39,15 \mathrm{a}$ & $2.717 \mathrm{a}$ \\
\hline CV $(\%)$ & 12,5 & 5,5 & 1,8 & 2,6 & 7,4 \\
\hline
\end{tabular}

Médias seguidas pela mesma letra não diferem entre em si pelo teste de Tukey a 5\% de probabilidade.

A semeadura realizada na primeira época $\mathrm{E}_{1}$ resultou na menor população final de plantas em comparação as três últimas épocas de semeadura do trigo $(10,17 \mathrm{e}$ $24 / 03 / 2013$ ), porém não se diferenciou da época $E_{2}$. Por sua vez, a maior massa de 1000 grãos foi obtida quando a semeadura do trigo foi realizada nos dias das épocas $E_{2}, E_{3}$ e $E_{5}$, enquanto que a menor massa de 1000 grãos foi obtida na semeadura realizada em na época $E_{4}$ (Tabela 2).

A semeadura de trigo realizada nas épocas $E_{2}$ e $E_{5}$ resultou nas maiores produtividades de grãos de trigo, enquanto que as menores produtividades de grãos foram obtidas com as épocas $\mathrm{E}_{3}$ e $\mathrm{E}_{4}$; as menores médias das épocas $E_{3}$ e $E_{4}$ estão relacionadas com a população final e o aumento de plantas por $\mathrm{m}^{2}$ onde a competição por luz e nutrientes podem ter influenciado na baixa produtividade. $\mathrm{A} \mathrm{E}_{1}$ obteve a menor produtividade se diferindo estatisticamente das épocas $\mathrm{E}_{2}, \mathrm{E}_{4}$ e $\mathrm{E}_{5}$, porém, não se diferenciou da época $E_{3}$. A baixa produtividade está relacionada à população final; na época $E_{1}$ foi constatada a menor média para a população de plantas por $\mathrm{m}^{2}$ (Tabela 2$)$.

A menor produtividade de grãos verificada na quarta época de semeadura está relacionada ao menor tamanho dos grãos de trigo, como pode ser constatado pela menor massa de 1000 grãos obtido nesta época de semeadura (Tabela 2). A massa de 1000 grãos é um dos principais componentes de produção que influenciam na obtenção de elevados índices de produtividades, visto que essa variável está diretamente correlacionada com a produtividade de grãos.

Os resultados obtidos neste estudo indicam que o rendimento de grãos de trigo pode ser influenciado pela época de semeadura. De acordo com Yan e Holland (2010), o potencial de rendimento de grãos depende de fatores genéticos e ambientais, bem como da interação entre ambos, o que resulta em expressivas diferenças no desempenho das cultivares quando cultivadas em diferentes épocas e condições ambientais. Guarienti et al. (2005) constataram que as condições ambientais de precipitação e temperatura influenciaram no peso hectolítrico, na massa de mil grãos e na produtividade da cultura. Silva et al. (2011) avaliando a interação entre genótipos e ambiente associados a épocas de semeadura em duas regiões tritícolas do Estado do Paraná verificaram que o rendimento de grãos está relacionado diretamente com os fatores climáticos, especialmente, com os índices de precipitação pluvial durante o ciclo da cultura. De acordo com Prela-Pantano et al. (2005), os índices de precipitação pluvial durante o período de espigamento e de formação e enchimento dos grãos possuem relação com a produtividade do trigo. A falta de água nessas fases de desenvolvimento da cultura pode reduzir o número de grãos por espiga $\mathrm{e}$, consequentemente, o rendimento da cultura (FRANCESCHI et al., 2010).

\section{Conclusões}

Semeaduras realizadas na primeira e na última semana de março em Santo Antônio do Leverger-MT, na região Centro-Sul Mato-Grossense, proporcionam as maiores produtividades de grãos em trigo de sequeiro.

\section{Referências Bibliográficas}

BASSOI, M. C.; BRUNETTA, D.; DOTTO, S. R.; SCHEEREN, P. L.; CAETANO, V. R.; TAVARES, L. C. V.; MIRANDA, L. C. Características e desempenho agronômico no Paraná da cultivar de trigo BRS 220. Pesquisa Agropecuária Brasileira, Brasília-DF, v. 40, n. 2, p. 193-196, 2005.

BORÉM, A.; SCHEEREN, P. L. Trigo: do plantio à colheita. Viçosa-MG: Editora UFV, 2015. 260 p.

CONAB. COMPANHIA NACIONAL DO ABASTECIMENTO. Acompanhamento da safra brasileira de grãos - safra 2016/2017- quarto levantamento. Brasília-DF: Conab, 2017. Disponível em: <http://www.conab.gov.br/OlalaCMS/uploads/arquivos/16_01 _12_09_00_46_boletim_graos_janeiro_2016.pdf >. Acesso em: 02 fev. 2017. 
CUNHA, G. R.; PIRES, J. L. F.; VARGAS, L. Trigo no Brasil: Bases para produção competitiva e sustentável de trigo no Brasil. Passo Fundo-RS: Embrapa Trigo, 2011, p. 20 -289.

FRANCESCHI, L.; BENIN, G.; MARCHIORO, V. S.; MARTIN, T. N.; SILVA, R. R.; SILVA, C. L. Métodos para análise de adaptabilidade e estabilidade em cultivares de trigo no estado do Paraná. Bragantia, Campinas-SP, v. 69, n. 4, p.797-805, 2010.

GUARIENTI, E. M.; CIACCO, C. F.; CUNHA, R. G.; DEL DUCA, L. J. A.; CAMARGO, C. M. O. Efeitos da Precipitação pluvial, da umidade relativa do ar e de excesso e déficit hídrico do solo no peso do hectolitro, no peso de mil grãos e no rendimento de grãos de trigo. Ciência e Tecnologia de Alimentos, Campinas-SP, v. 25, n. 3, p. 412-418, 2005.

PRELA-PANTANO, A.; PEREIRA, A. R.; CARAMORI, P. $H$. Influência dos fenômenos $\mathrm{El}$ Niño e La Niña na produtividade de trigo no Estado do Paraná. Revista Brasileira de Agrometeorologia, Piracicaba-SP, v. 13, n. 3, p. $326-337,2005$.

RIBEIRO, T. L. P.; CUNHA, G. R.; PIRES, J. L. F.; PASINATO, A. Respostas fenológicas de cultivares brasileiras de trigo à vernalização e ao fotoperíodo. Pesquisa Agropecuária Brasileira, Brasília-DF, v. 44, n. 5, p. 13831390, 2009.
ROOZEBOOM, K. L.; SCHAPAUGH, W. T.; TUINSTRA, M. R.; VANDERLIP, R. L.; MILLIKEN, G. A. Testing wheat in variable environments: genotype, environment, interaction effects, and grouping test locations. Crop Science, MadisonUSA, v. 48, n. 3, p. 317-330, 2008.

SANTOS, H. G.; JACOMINE, P. K. T.; ANJOS, L. H. C.; OLIVEIRA, V. A.; LUMBRERAS, J. F.; COELHO, M. R.; ALMEIDA, J. A.; CUNHA, T. J. F.; OLIVEIRA, J. B. Sistema brasileiro de classificação de solos. 3. ed. Brasília-DF: Embrapa Solos, 2013. 353 p.

SILVA, R. R.; BENIN, G.; SILVA, G. O.; MARCHIORO, V. S.; ALMEIDA, J. L.; MATEI, G. Adaptabilidade e estabilidade de cultivares de trigo em diferentes épocas de semeadura, no Paraná. Pesquisa Agropecuária Brasileira, Brasília-DF, v. 46, n. 11, p. 1439-1447, 2011.

USDA. UNITED STATES DEPARTMENT OF AGRICULTURE Wheat: world markets and trade. Washington-USA: USDA, 2017 Disponível em: <https://apps.fas.usda.gov/psdonline/circulars/grainwheat.pdf $>$. Acesso em: 04 mar. 2017.

YAN, W.; HOLLAND, J. B. A heritability-adjusted GGE biplot for test environment evaluation. Euphytica, Wageningen, v. 171, n. 3, p. 355-369, 2010. 